\title{
Predicting Velocity Growth: A Time Series Perspective
}

\author{
SCOTT E. HEIN and PAUL T. W. M. VEUGELERS
}

\begin{abstract}
- NE important issue involved in the choice of a monetary aggregate for policy purposes is the predictability of the relationship between the aggregate and nominal GNP growth. This article examines the predictability of recent M1 velocity growth to assess claims that the relationship between $\mathrm{M} 1$ and nominal GNP has deteriorated. ${ }^{1}$
\end{abstract}

\section{WHY PREDICT VEIOCITY GROWIII}

The quantity equation of exchange states that nominal GNP $(\mathrm{Y})$ is identically equal to the product of the money stock $(M)$ and its velocity $(V)$, or rate of turnover. Expressed in terms of growth rates, the relationship is equally straightforward: the growth of nominal GNP is equal to the sum of the growth in the money stock and the growth in its velocity.

If we take the ability to achieve a desired money growth objective as given, the success in achieving a nominal GNP goal is based simply on the precision with which velocity growth can be forecast. For example, if monetary authorities know that $\mathrm{M} 1$ velocity growth will be 3.0 percent next year, a goal of 8.0 percent nominal GNP growth simply requires $\mathrm{Ml}$ growth of 5.0 percent. The uncertainty attached to the GNP objective then depends on the uncertainty attached to predicting velocity growth.

\section{MOUR WAYS TO PREDICT VELOCITI GDOWTH}

This paper evaluates four different time series techniques used to predict future velocity growth over the

Scott E. Hein is an associate professor of finance at Texas Tech University: Paul T. W. M. Veugelers is a professor of economics at Erasmus Universitu, Rotterdam, The Netherlands. This article was written while Professor Hein was a senior economist and Professor Veugelers was a visiting scholar at the Federal Reserve Bank of St. Louis.

${ }^{1}$ For an alternative analysis of this issue, see John A. Tatom "Was the 1982 Velocity Decline Unusual?" this Review (August/September 1983), pp. 5-15. period II/1975-I/1983, roughly the last two full business cycles. These techniques use only information available at the time the forecast is made, the same constraint facing a policymaker. Because of this constraint, we have restricted the class of forecasting models to time series models, whose forecasts are determined solely on the past behavior of velocity growth itself. $^{2}$

It is important to note that the four techniques differ with respect to the relative weights attached to velocity growth behavior in the recent and distant past. Some techniques' forecasts of velocity are influenced more heavily by recent trends in velocity growth, while other techniques use longer trends. In addition, the techniques differ in terms of their computational ease and statistical sophistication.

\section{Sample Mean Forecast}

The technique that attaches the greatest weight to the more distant past and is one of the simplest is the sample mean forecasting technique. With this technique, next quarter's velocity growth is forecast to equal the average of velocity growth from II/1959 to the period immediately preceding the forecast (see box on opposite page, equation 1 ). ${ }^{3}$

Thus, for example, the forecast of velocity growth in I/1983 is simply the average of velocity growth from II/1959 to IV/I982. We refer to this forecast as the sample mean forecast and use the superscript (SM) to distinguish it from others.

The sample mean forecasting procedure is not as naive as it may appear on the surface. If velocity growth

\footnotetext{
${ }^{2}$ This information constraint limits the usefulness of econometric models that utilize contemporaneous observations of other deter mining variables, because forecasting velocity growth in such a framework necessitates that forecasts of these determining variables also be made. As a result of this complication, we ignore this class of models.

"The paper uses the new $M 1$ measure, which is only available since 1959. Also, because this study was completed before July 1983 , the GNP series used does not include the latest revisions.
} 


\section{Alternative Velocity Forecast Procedures ${ }^{1}$}

Sample Mean Forecast (SM)

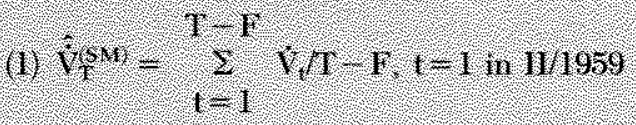

Triple Exponential Snoothing Eorecast (XS)

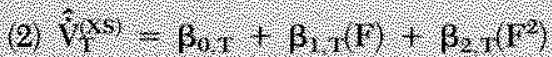

Kalman Wher Forecast $(\mathbf{K O})^{2}$

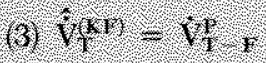

Random Walk Forecast (RW)

4) $v(m w)=\sqrt{t} \cdot r$

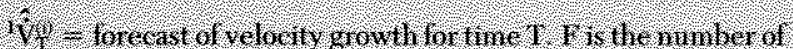
periods into the forture over which the procedure forecats: Information on velecil, growth is presumed to be stallable only firough period T - I

it 1 - estmat of perminent velocity growth at time 1 - I using Kalman filter approach.

Huctuates randomly about a fixed mean, then it is said to be white noise. In this case, the best forecast for velocity growth at any point in the future is simply the sample mean. ${ }^{4}$ There is evidence to suggest that veloc-

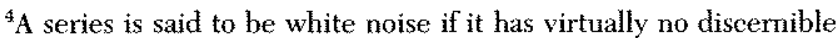
pattern to it. If such a series is denoted by $\varepsilon_{\mathrm{t}}$, then this series is white noise if correlation $\left(\varepsilon_{\mathrm{r}}, \varepsilon_{\mathrm{s}}\right)=0$ for all $t \neq s$ and if the expected value of $\varepsilon_{t}$ is constant for all $t$. See $C . W$. J. Granger, Forecasting in Business and Economics (Academic Press, 1980), esp. pp. 41-42.

The long-run properties of the "St. Louis equation" also suggest that velocity growth will be constant in the long-run steady state. Recent variations of this equation are represented by:

$$
\text { (4) } \dot{Y}_{t}=\beta_{0}+\sum_{i=0}^{J} \beta_{i}^{t} \dot{M}_{\varepsilon-i}+\sum_{i=0}^{K} \beta_{i}^{\prime \prime} \dot{\mathrm{E}}_{\mathrm{l}-\mathrm{i}}+\varepsilon_{\mathrm{t}}
$$

where $\dot{\mathrm{Y}}_{\mathrm{t}}$ is GNP growth, $\dot{\mathrm{M}}_{\mathrm{t}}$ is money stoek (M1) growth, $\dot{\mathrm{E}}_{\mathrm{t}}$ is high-employment expenditure growth, the $\beta$ coefficients are constants and $\varepsilon_{\mathrm{t}}$ is a randon term. Statistical estimation of this equation generally has supported the long-run propositions that

$$
\underset{i=0}{J} \beta_{i}^{r}=1 \text { and } \underset{i=0}{\sum} \beta_{i=0}^{\prime \prime}=
$$

Placing these steady-state restrictions in equation 4 yields the steady-state result (for $\dot{\mathrm{M}}_{\mathrm{t}}=\dot{\mathrm{M}}_{\mathrm{t}-\mathrm{i}}=\ldots$ )

(4) $\dot{\mathrm{Y}}_{\mathrm{t}}=\beta_{0}+\dot{\mathrm{M}}_{\mathrm{t}}$,

or rearranging,

$\left(4^{t r}\right) \dot{\mathrm{Y}}_{\mathrm{t}}-\dot{\mathrm{M}}_{\mathrm{t}}=\dot{\mathrm{V}}_{\mathrm{t}}=\beta_{\mathrm{B}}$

In the long rum, then, the $\mathrm{St}$. Louis equation suggests velocity growth will be constant, in which case the best forecast is again ity growth was white noise in the I/1959-1/1975 period. ${ }^{5}$

\section{Exponential Smoothing Forecast}

The second forecasting technique considered is a more complicated procedure called triple exponential smoothing (XS). Forecasters frequently use smoothing procedures to improve upon mean forecasts. When the mean of the underlying series is subject to change,

the average level of velocity growth. For a recent discussion of this equation, see Dallas S. Batten and Daniel L. Thornton, "Polynom" inal Distributed Lags and the Estimation of the St. Louis Equation," this Review (April 1983), pp. 13-25.

The conclusion that velocity growth is white noise is consistent with the evidence in John P. Gould and Charles R. Nelson, "The Stochastic Structure of the Velocity of Money, American Economic Review (June 1974), pp. 405-18. They find that the log of the level of velocity is a random walk,

$\ln V_{t}=\ln V_{t-1}+8+\mu$

Thus, the difference in log levels, which is a multiple of growth rate of velocity - the variable in our study - can be expressed as a white noise series:

la $V_{t}-\ln V_{t-1}=8+\mu_{t}$

They found, using annual data over a longer time period that $\delta$ was not different from zero. Our evidence for quarterly data after 1959 suggests this is not true. In either case, velocity growth lluctuates randomly about a fixed value. 


\section{Triple Exponential Forecast Technique}

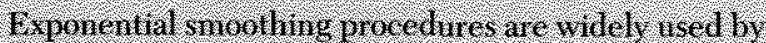

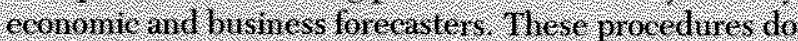

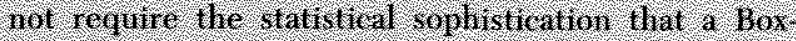

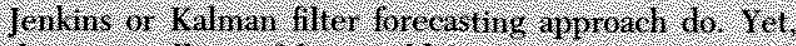

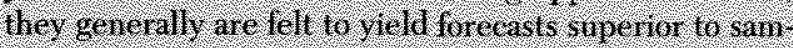

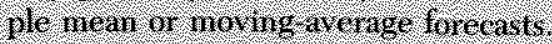

The trple expone ntill s noothing procedure employed in foreating velocht growth starts by whenhing thee sinoulted stansiles?

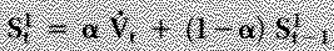

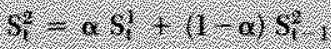

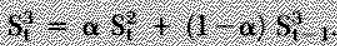

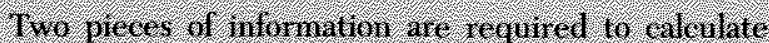

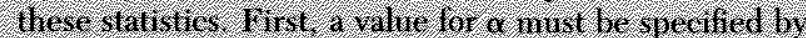

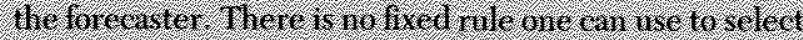

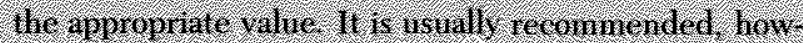

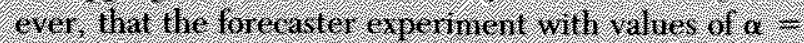

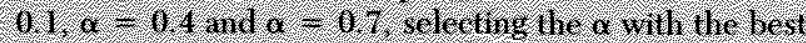

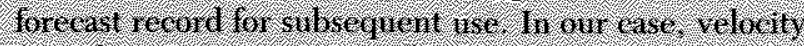

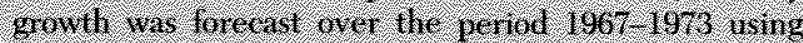

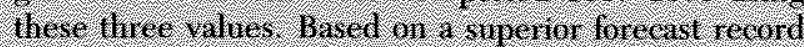

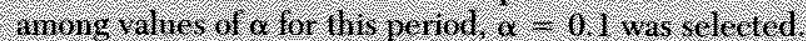

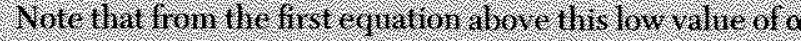

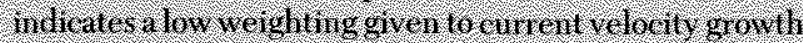
developments and a ligh weighting given to he nore Atstant Wast:

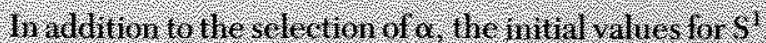
$5^{2} \mathrm{and}^{3}$. re required, 1 hest vlues wore all sel equal 10

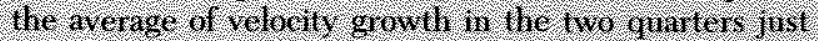
Getort the forecasting prosedire was hinted, whit is $111973 \mathrm{in}$ ont case.

The next ctep requires lie calchialion of three fored st ing coenterents that are based on whe smouthing statish ics:

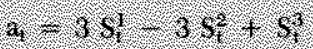

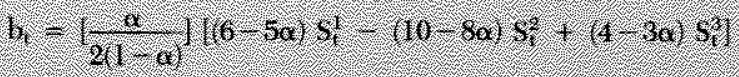

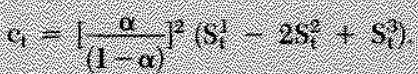

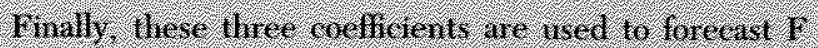
perrods antad or period I, based on he folluwing rela vionshin

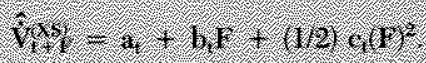

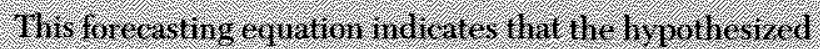

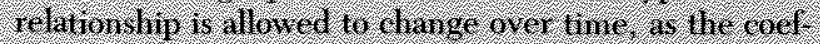

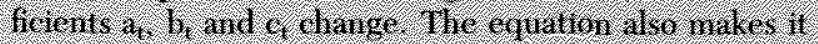

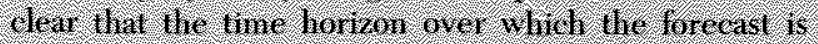

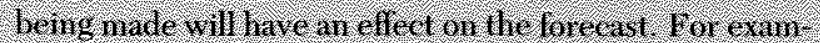

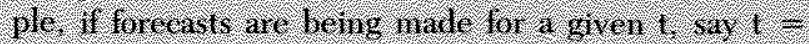

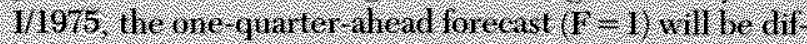

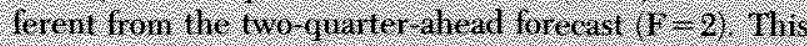

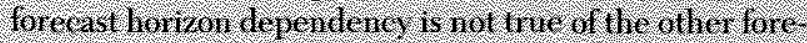

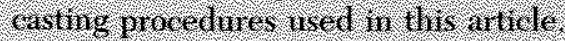

these procedures, which give more weight to recent observations, are felt to be superior to mean or moving-average forecasts, because such procedures more quickly recognize changing conditions. Yet the procedure is not statistically derived and, for that reason, is somewhat ad hoc (see above for more detailed description). The particular smoothing procedure employed here postulates that velocity growth is related to time in the specific fashion shown on page 35, equation 2 .

The coefficients from the triple exponential smoothing procedure are allowed to change through time in a way that incorporates past velocity behavior, though it allows for the influence of past effects to decay rapidly. Once coefficients are calculated, they are simply plugged into the forecast equation (page 35 , equation 2) to obtain a forecast of future velocity growth.

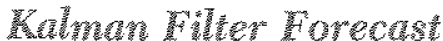

The third forecasting scheme considered is the Kalman filter (KF) technique. ${ }^{6}$ This procedure postulates that velocity growth is subject to two kinds of "shocks": temporary and permanent. ${ }^{7}$ The Kalman filter tech-

\footnotetext{
"The procedure is explained in Clemens J. M. Kool "Statistical Appendix A: The Multi-State-Kalman Filter Method," appended to Eduard J. Bomboff, "Predicting the Price Level in a World that Changes all the Time," in Karl Brunner and Allan H. Meltzer, eds., Economic Policy in a World of Change, Carnegie-Rochester Conference Series on Public Policy, Vol. 17 (1982), pp. 39-46.

IIt can be represented as two equations:
(5) $\dot{V}_{t}=\dot{V}_{t}^{P}+\varepsilon_{t}$
(6) $\dot{V}_{t}^{p}=\dot{V}_{t-1}^{p}+x_{t}$,

where $\dot{V}_{f}^{\mathrm{x}}$ is the permanent level of velocity growth at timet. The $\varepsilon_{\mathrm{t}}$ term represents a transitory shock to the level of velocity growth and the $\mu_{\mathrm{t}}$ represents a permanent shock to the level of velocily growth
} 
nique further differentiates between small and large shocks, so that four states are possible: (1) small and temporary, (2) large and temporary, (3) small and permanent and (4) large and permanent. Based on the past history of the growth of velocity, the Kalman filter technique estimates the probability of each of the four states and forecasts future velocity growth based on a weighted average of the estimated permanent level of velocity growth under each of the four various states. The result is shown in the box on page 35 , where $\dot{V}_{T-F}^{\mathrm{P}}-\mathrm{F}$ represents the permanent level of velocity growth immediately prior to the forecast.

This model of velocity behavior can be shown to correspond to an integrated moving-average model of the form IMA $(1,1)$. This correspondence indicates that recent velocity growth information is used more heavily in the development of this forecast than either of the two forecasting techniques considered thus far.

\section{Pandom Walk torecast}

As a fourth alternative, a random walk model (RW), which places even greater weight on recent developments, is assessed. This model holds that the change in velocity growth is completely random, implying that the best forecast of velocity growth in the future is the current level of velocity growth (as shown in equation 4 , page 35). The random walk model stands in sharp contrast to the sample mean model. It suggests that knowledge of velocity growth in the distant past is irrelevant in forecasting the future because all relevant information is already contained in the most recent observation. The sample mean model, on the other hand, weights observations from the distant past equal to the most recent ones. ${ }^{8}$

\section{THE POPECASTS}

These four models were used to forecast velocity growth from II/1975 to I/1983 over two alternative time horizons. The first forecasts were simply one-quarter forecasts of velocity growth. The other forecasts were for velocity growth over the next four quarters. For the

\footnotetext{
${ }^{8}$ The random walk model of velocity growth, or variations that emphasize mote recent velocity growth, seem to have gained wider acceptance because velocity growth recently has been "abnomally" sluggish. As an example of forecasters who heavily weight recent velocity behavior, consider this statement in Robert A. Brusca Financial Markets, Irving Trust (July 15, 1983) ". . MI's velocity might even increase in the second quarter [of 1983]. If this happens, the Fed is more likely to be concerned with $\mathrm{Ml}$ 's growth." This statement suggests that velocity growth developments in the second quarter of 1983 will heavily influence velocity growth in the third quarter.
}

latter forecasts, no information from the intervening four quarters is used in any of the forecast procedures. ${ }^{9}$ The forecast of velocity growth over the next four quarters made at time $t=\mathrm{T}-4$ is denoted by $\hat{\mathrm{V}} 44_{\mathrm{T}}^{(i)}$, where $\mathrm{i}=(\mathrm{SM}, \mathrm{KF}, \mathrm{XS}, \mathrm{RW})$.

\section{The One-Quarter Forecases of Velocity Growth}

Table 1 lists actual quarterly velocity growth and the forecast errors (predicted minus actual) from the four alternative forecasts for 11/1975-I/1983, where each forecast was developed conditionally on information pertaining to velocity growth up to the period being forecast. For example, the sample mean forecast $\left(\hat{\mathrm{V}}_{\mathrm{T}}^{\mathrm{SM}}\right)$ for II/1975 was 2.79 percent, the average level of velocity growth from $\mathrm{II} / 1959$ to $\mathrm{I} / 1975$. Since velocity growth was actually 3.77 percent in $I I / 1975$, the mean forecast underestimated velocity growth by 0.98 percentage points. The triple exponential smoothing procedure $\left(\hat{\dot{V}}_{\mathrm{T}}^{\mathrm{XS})}\right)$ and the Kalman filter technique $\left(\hat{\dot{V}}_{\mathrm{T}}^{\mathrm{KF}}\right)$ use these same observations of velocity growth to obtain forecasts of 1.31 percent and 1.45 percent, respectively. ${ }^{10}$ Both underestimated velocity growth in II/1975 by larger magnitudes than the sample mean forecast. The random walk forecast $\left(\dot{\mathrm{V}}_{\mathrm{T}}^{(\mathrm{RW})}\right)$ of a 1.36 percent decline for $I / 1975$ simply reflects the fact that velocity fell at a 1.36 percent rate in $\mathrm{I} / 1975$. As shown in table 1, the random walk model yielded the largest forecast error in $\mathrm{II} / 1975$ ( 5.12 percentage points).

Table 1 lists statistics that summarize the different forecasting performances of the different models: the mean absolute forecast error and the root-meansquared error. ${ }^{11}$ The closer the forecast is on average to

${ }^{9}$ In the case of the four-quarter horizon, we forecast velocity growth over the next four-quarter period, not the quarterly velocity growth four quarters hence. That is, if $t$ is the period fron which the forecast is made, we forecast $\left(\ln V_{t+4}-\ln V_{t}\right) \times 100$, not $(\ln$ $\left.V_{t+4}-\ln V_{t+3}\right) \times 400$. For later reference, it is useful to recognize that velocity growth over the next four quarters is equal to average velocity growth over the next four quarters:

$$
\begin{aligned}
& \left(\ln V_{t+4}-\ln V_{t} \times 100=\left[\left(\ln V_{t+1}-\ln V_{t+3}\right)+\left(\ln V_{t+3}\right.\right.\right. \\
& \left.\left.-\ln V_{t+2}\right)+\left(\ln V_{t+2}-\ln V_{t+1}\right)+\left(\ln V_{t+1}-\ln V_{t}\right)\right] \times 100 \\
& =\left[\dot{V}_{t+4}+\dot{V}_{t+3}+\dot{V}_{t+2}+\dot{V}_{t+1}\right] / 4 .
\end{aligned}
$$

${ }^{10}$ The triple exponential smoothing technique was initiated in II/ 1973 using the average of velocity growth in IV/1972 and $1 / 1973$. (See box on opposite page for more details.)

${ }^{11}$ Let $\varepsilon_{\mathrm{t}}$ be a forecast error for period $t$. Then, the mean absolute forecast error is $\stackrel{N}{\Sigma}\left|\varepsilon_{\mathrm{t}}\right| / \mathrm{N}$; and the root-mean-squared error is $\left(\sum_{t=1}^{N}\left(\varepsilon_{t}\right)^{2} / N\right)^{t / 2}$ 


\section{Table 1 \\ One-Quarter Velocity Growth Forecasts and Summary Statistics}

\begin{tabular}{|c|c|c|c|c|c|}
\hline \multirow[b]{2}{*}{ Peniod } & Acual & \multicolumn{4}{|c|}{ Forecast Errors } \\
\hline & y. & 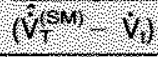 & $w^{(x)} y^{\text {sit }}$ & $\left.v_{1}+v^{\prime}\right)$ & $\left.\left(v_{T}^{\left(w^{w}\right.}\right), v_{i}\right)$ \\
\hline 114975 & $3.77 \%$ & $10,98 \%$ & $2,246 \%$ & $2,32 \%$ & ४ $512 \%$ \\
\hline 11/1975 & 8.64 & 45.84 & 6.98 & .604 & 4.87 \\
\hline 119975 & 780 & 4.93 & 4,30 & 2208 & 9.81 \\
\hline 11976 & 6.49 & 3.50 & 1,74 & 0,04 & 1,33 \\
\hline 111976 & 10.34 & 3.35 & 46.7 & 6.90 & 6.83 \\
\hline 1119976 & 42.84 & 0.012 & 0.91 & 0.55 & 318 \\
\hline W/976 & 2.52 & 0.45 & 0,92 & 4057 & 40,33 \\
\hline 11971 & 4.49 & 4,53 & $\checkmark 147$ & 47,3 & 4,98 \\
\hline 101977 & 581 & 2808 & 2,11 & 2,24 & 1,32 \\
\hline 111977 & 45,70 & 2067 & 468 & $\checkmark>108$ & 90,12 \\
\hline N/1977 & 4,37 & 4,43 & 5.93 & 465 & 706 \\
\hline 11978 & 40,71 & 2.20 & 2,18 & $1,1,22$ & $\begin{array}{l}200 \\
0\end{array}$ \\
\hline 119970 & 1172 & 4075 & 4963 & 10.89 & .1101 \\
\hline 1119978 & 3.94 & .085 & 0.86 & 4425 & 778 \\
\hline 111978 & 6.92 & 3.02 & 4227 & 3,02 & 4298 \\
\hline $1 / 1079$ & 4427 & $4+13$ & 41,13 & 4,13 & $\checkmark 264$ \\
\hline 111979 & $\longdiv { 2 6 5 }$ & 4800 & 4787 & 47,49 & 4692 \\
\hline $11 / 1979$ & 3.54 & 0.46 & 0.56 & 00.89 & 6.19 \\
\hline $14 / 1979$ & 3,30 & .021 & 0,25 & 0.43 & 4025 \\
\hline$\sqrt{1980}$ & 4.78 & $4 \longdiv { 6 9 }$ & 47,7 & 4,121 & $4 \longdiv { 4 8 }$ \\
\hline 117980 & 288 & 40.27 & 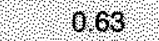 & 4,14 & $\sqrt{194}$ \\
\hline 1117980 & 3.00 & 4614 & 628 & 666 & 8687 \\
\hline W19800 & 4327 & 4023 & 4,06 & 4079 & -630 \\
\hline 11981 & 1340 & -1036 & 11174 & 41016 & 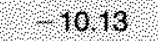 \\
\hline 119881 & 4404 & $7,7,20$ & $\checkmark 908$ & 4747 & 47,44 \\
\hline 1111981 & 10.51 & 1745 & 807 & -753 & $\checkmark 1456$ \\
\hline 110081 & $\checkmark 271$ & 4587 & $? 746$ & 4613 & 1322 \\
\hline 11982 & 11,28 & 4437 & 10992 & 13.44 & 1857 \\
\hline $11 / 1982$ & 3.29 & 4035 & 4.91 & 12228 & 41457 \\
\hline $111 / 982$ & 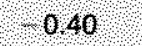 & 3.34 & 025 & 304 & ? 3.69 \\
\hline 111982 & 10.29 & 1320 & 9.94 & 5144 & 990 \\
\hline 14983 & 45,06 & 783 & 0.93 & 585 & s.23 \\
\hline & & & summ & Statistios & \\
\hline Mean AI & Error & 4.13 & 423 & 429 & 580 \\
\hline Fool $\mathrm{Ne}$ & Hared Eror & 5.58 & 563 & 564 & 740 \\
\hline Fraction & $18010 \mathrm{te}$ & & & & \\
\hline $4(A) B$ & & 001 & 000 & 008 & 000 \\
\hline (B) V & & 099 & 0.36 & 0.47 & 000 \\
\hline$(\mathrm{C}) \mathrm{C}$ & & 0.04 & 0,64 & 0.50 & 100 \\
\hline
\end{tabular}

the actual growth rate, the smaller each of these summary measures will be. Thus, the size of each statistic provides a criterion by which to judge the respective abilities to forecast velocity growth.

In general, the models that place greater weight on the more recent observations perform worse. Compare, for example, the extremes represented by the sample mean and random walk models. The sample mean attaches the smallest relative weights to recent observations; its forecast record is generally the best. The random walk model, which attaches the greatest weight to recent developments, has the worst forecasting record with by far the largest mean absolute and root-mean-squared errors. 
The table shows little difference in the forecast records of the sample mean, the triple exponential smoothing and the Kalman filter procedures, however. While the sample mean forecast generally does slightly better than the other two, the difference is not great at all. ${ }^{12}$ Thus, it appears that knowing how velocity growth behaved this quarter provides no more information about how it will behave next than its behavior in the distant past.

Table 1 shows that the decomposition of the forecast error due to bias is less than 5 percent for each of the separate forecast procedures. ${ }^{13}$ Forecasts yield a large fraction of the error due to bias when the mean of the forecast series is different from the mean of the actual series being forecast. The small fraction of the error due to bias in table 1 is evidence that, regardless of the forecast procedure, the mean of the velocity growth forecasts is quite close to the mean of actual velocity growth over the period II/1975-I/1983. ${ }^{14}$ The fraction of the error due to variance increases when the series to be forecasted and the forecasts themselves have very different variances. The large fraction of error due to variance for the sample mean forecast $(\hat{\dot{V}} \mathrm{~T}$ (SM) $)$ confirms that the variance of quarterly velocity growth is much greater than the variance of the mean of velocity growth.

Regardless of which forecast model is considered, the quarterly prediction record is not impressive. Both the mean absolute error and the root-mean-squared error are quite large for each model. The root-meansquared error for the sample mean forecast, for example, suggests a 95 percent confidence range of plus or minus 11.2 percent. Thus, based on these different

\footnotetext{
${ }^{12}$ We tested whether any one forecist procedure conld improve upon another by regressing the forecast errors from one model on the difference in the forecasts (see C. W. J, Ginger and Paul Newbold, Forecasting Economic Time Sertes (Acadenic Press, 1977), esp. pp. 268-78. In general, we found nothing to statistically differentiate the sample mean, triple exponential and Kalman filter forecasts. None of these forecast procedures could improve statistically upon the others. Each of these three forecast procedures, however, was found to improve upon the random walk model, whereas the random walk model could not aid in explaining the other forecasts. In sum, there is little statistical evidence to differentiate among the sample mean, triple exponential and the Kalman filter forecasts; yet, all are superior to the random walk model.

${ }^{13}$ On the decomposition of forecast error, see C. W. J. Granger and P. Newbold, "Some Comments on the Evaluation of Economic Forecasts, Applied Economics (1973), pp. 35-47.

1.the mean forecast arrors for the sample mean, triple exponential smoothing, Kalman filter and random walk forecasts are 0.53 , $0.34,0.97$ and 0.12 , respectively. This indicates that all of the models slightly overpredicted velocity growth on average for the period $\mathrm{H} / 1975-1 / 1983$.
}

forecasting procedures, it appears that forecasting quarterly velocity growth with precision is quite difficult. This suggests that the precision that monetary policymakers have in achieving short-run nominal GNP growth objectives is not great. ${ }^{15}$

The lack of precision in achieving short-run GNP growth objectives stands in sharp contrast to recent efforts to require the Federal Reserve to announce GNP growth targets. For example, a recent Business Week editorial urged that, "Chairman Volcker should be required to say what the Fed expects the quarterly growth of nominal GNP to be, especially how its forecast relates to money growth targets. . . . No one knows better than Volcker that the economy is much too complex to be guided simply by monitoring movements in monetary aggregates alone" (emphasis added). ${ }^{16}$

The evidence provided here suggests that little would be added by adopting an explicit GNP growth objective. M1 velocity growth apparently fluctuates randomly around a level of 2 to 3 percent, so that a monetary target for Ml can easily be translated into a GNP objective by adding 2 to 3 percent to it. The difficulty with adopting such an objective is that the random velocity growth fluctuations are quite large, indicating that the Federal Reserve alone cannot closely achieve a particular short-run GNP target that it or anyone else would choose. In this regard, "attempts to targt GNP within a narrow range would, deliberately or not, provide an unwarranted sense of omnipotence for monetary policy." 17

\section{Velocity Growh Since 1982}

For the period as a whole, the sample mean forecast works as well as any other procedure, an observation consistent with the notion that velocity growth fluctuates randomly about a fixed value. The table does show large forecast errors for the sample mean model over the recent period I/1982-1/1983, however. For instance, while velocity contracted at a substantial 2.28 percent rate over this period, the sample mean model

\footnotetext{
"In this vein, Karl Brumer, "Ilas Monetarism Failed?" The Cato Journal (Spring 1983), p. 42, has stated that ". . . discretionary policies attempting to offset observed or anticipated changes in velocity most probably raise, on average, the variability of changes in nominal GNP."

${ }^{16}$ "More Details from the Fed,"Business Week, Angust 1, 1983, p. 104.

${ }^{17}$ Statement by Paul Voleker, Chairman of the Board of Governors of the Federal Reserve System, before the Subcommittee on Domestic Monetary Policy of the House Committee on Banking, Finance and Urban Affairs, Alugust 1983, processed.
} 
was forecasting growth of about 3.00 percent. This anomalous pattern of velocity growth resulted in a very large root-mean-squared error of 9.52 percent for this period - almost twice that of the full period. While this may seem sufficient grounds to question the usefulness of such a model of velocity growth, a number of considerations suggest that it is premature to conclude that the sample mean characterization has become invalid.

To begin with, the other forecasting procedures also have deteriorated significantly over this period. The root-mean-squared errors for the triple exponential smoothing, Kalman filter and random walk forecasting models are 7.84 percent, 8.44 percent and 9.40 percent, respectively. All of these measures indicate much larger forecast errors than for earlier periods, as all of the models have had less success in forecasting recent developments. Velocity growth has become more volatile recently and the performance of the four forecast techniques has deteriorated accordingly. ${ }^{18}$

Moreover, even though the sample mean model performed worse than the other models since $1 / 1982$, this period is too short to attach great significance to such a finding. There have been other periods of similar length in the past, in which the sample mean did an inferior job; over the period 11/1975-I/1976, for example, both the Kalman filter and random walk models resulted in root-mean-squared errors considerably below that of the sample mean. Yet, as we have seen, for the full period the random walk model is clearly inferior and the Kalman filter is slightly worse than the sample mean model.

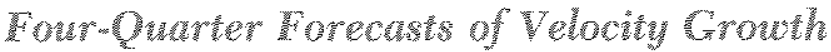

Because policy generally is concerned with periods longer than one quarter, the relevant issue for policy is prediction errors over longer time horizons, for exam-

\footnotetext{
Whe standard deviation of velocity growth is 6.26 percent for the 1/1982-I/1983 period - almost twice what it was for the period II/1975-1/1979, for example. This increased volntility makes it impossible to test statistically whether the mean of velocity growth has changed in the recent period, because the small sam. ple tests used to test such a hypothesis require assumptions of normality and equal cariance. Thus, while the mean of velocity growth for the $1 / 1982-1 / 1983$ period is smaller than it was in the earlier period, one cannot determine whether it is statistically different. It is thus too early to argue that the mean model is invalid. What may have changed is that the random shocks to velocity growth have simply gotten larger.

It is interesting to note that if one compares the mean of velocity growth over the period IV/1975-U/1983 with that of the preceding 32 cuarters, no assumption of equal variance is required because it is a large sample test. Comparing the means across these two sample periods, however, indicates that there is no statistical
}

ple, four-quarter periods. ${ }^{19}$ How do the different models generate such longer-run velocity predictions? The sample mean, Kalman filter and random walk forecast models yield forecasts that are independent of the forecasting horizon. At any specific point in time, each of these models project velocity growth to be a given value for the indefinite future. For example, the mean of velocity growth from IU/1959 to $/ / 1975$ was 2.79 percent. Thus, the forecast for $11 / 1975$ based on the sample mean model is 2.79 percent. Because this same growth is forecast to continue over the indefinite future, the sample mean forecast of velocity growth from IU/1975 to $\mathrm{I} / 1976$ also is 2.79 percent.

The triple exponential smoothing forecasts - unlike the other three techniques - are not independent of the forecast horizon, however. The forecast of velocity growth two quarters ahead is not the same as the forecast of velocity growth one quarter ahead. Thus the forecast of velocity growth for the next four-quarter period is defined to be the average of the one-periodahead, two-period-ahead, three-period-ahead and four-period-ahead quarterly velocity growth forecasts. In this way, all the models essentially are forecasting velocity growth over the next year based only on information available today.

Table 2 lists the actual velocity growth rates over the previous four quarters and the respective forecast errors for the same period. The forecast error at time $t$ is simply the difference between the velocity growth predicted at $t-4$ and the actual velocity growth at $t$. A comparison of tables 1 and 2 indicates, not surprising. $\mathrm{ly}$, that actual four-quarter velocity growth is much less volatile than one-quarter growth rates. The standard deviation of the quarterly growth rate is 5.54 percent; it is only 2.70 percent for the four-quarter velocity growth rate.

Irrespective of the forecast technique, the mean absolute error and the root-mean-squared error in table 2 also are both much smaller than their counterparts in table 1. For example, the root-mean-squared error from the sample mean forecast technique for the four-quarter velocity growth rate forecast is 50 percent smaller than the root-mean-squared error for the onequarter ahead forecast, decreasing the 95 percent confidence range from plus or minus 11.2 percent to plus or minus 5.5 percent. Similar reductions in the root-

difference in the means. This suggests that the sharp contraction in velocity growth since $1 / 1982$, has simply offset more rapid velocity growth for the period II/1975-IV/1981.

${ }^{10}$ Recall footnote 9 that shows that velocity growth over the next four quaters is equal to average anarterly velocity growth for the next four quarters. 
Table 2

Four-Quarter Velocity Growth Forecasts and Summary Statistics

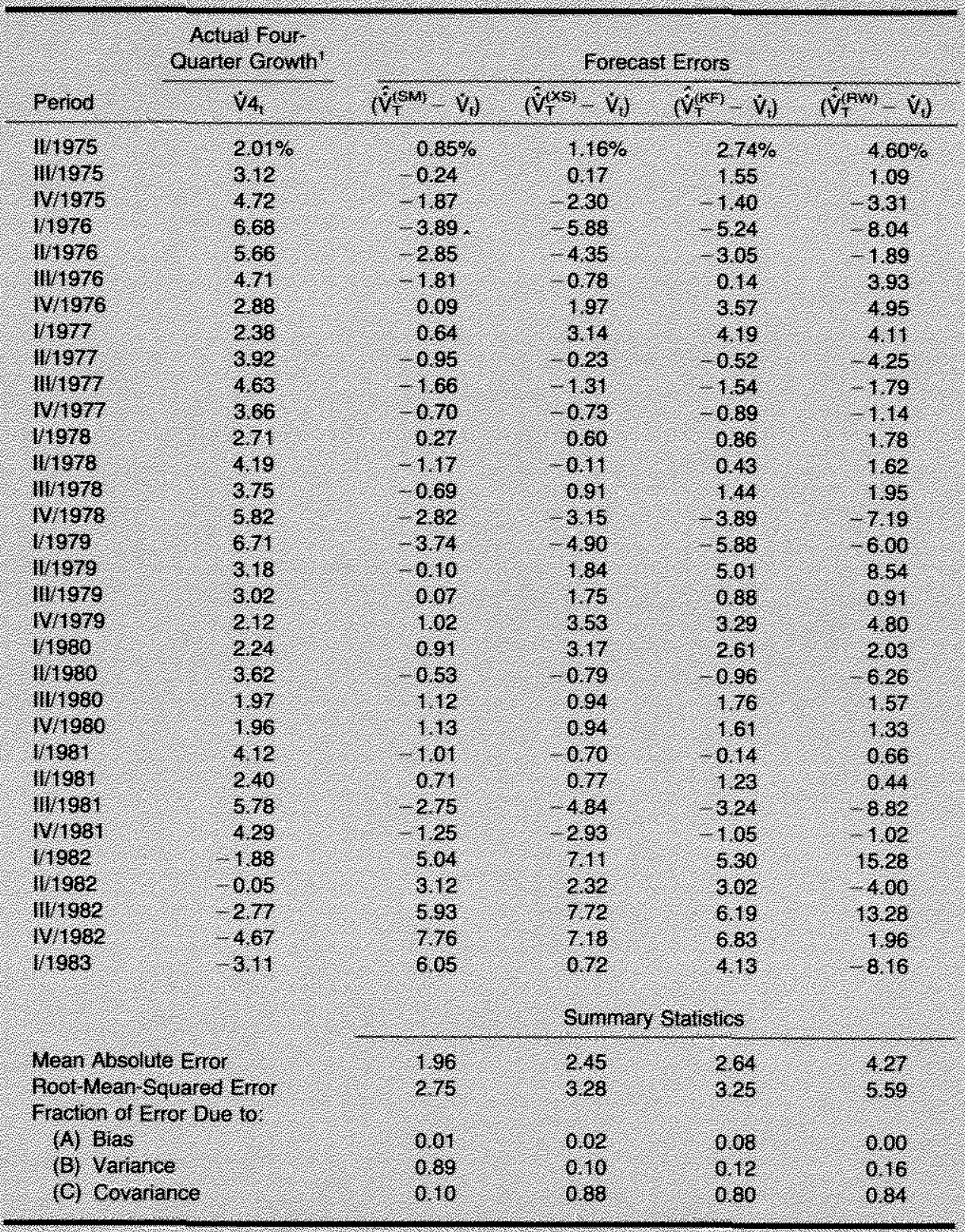

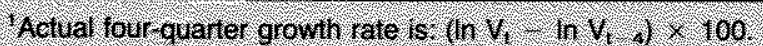

mean-squared error and the mean absolute error also are evident for the other forecast techniques.

In the case of four-quarter growth rate predictions, the sample mean forecast model still has the smallest root-mean-squared error and mean absolute error. Whereas there were hardly any differences in the root- mean-squared errors among the first three models for the one-quarter-ahead forecasts, the sample mean forecast has a root-mean-squared error for the yearly forecasts that is 15 percent smaller than either the exponential smoothing or the Kalman filter procedure. Thus, there is no longer-run forecasting gain associated 
with using these more sophisticated models. Moreover, the sample mean forecast continues to be much superior to the random walk forecast. ${ }^{20}$

Finally, while velocity growth forecast errors for four-quarter growth rates during 1982 are the largest in the sample period, large forecast errors of the opposite sign were experienced earlier. For example, fourquarter velocity growth was very strong through 1975 and early 1976, resulting in sizeable underpredictions. Similar developments occurred in late 1978 and early 1979..$^{21}$

\section{POLICY IMPLICATIONS PROM FORECAST RESULTS}

The evidence presented here is consistent with the hypothesis that quarterly velocity growth fluctuates randomly about a fixed mean. If this characterization is correct, then next quarter's velocity growth is best predicted by the sample mean. This is indeed what was found. None of the alternative time series models significantly improved upon the sample mean forecast. The fact that the sample mean forecast procedure itself did not do very well in forecasting one-quarter velocity growth does not discredit such a model, but suggests that the random short-iun shocks are quite large in nature.

What can be inferred from large variations in random shocks to velocity growth or their growing in magnitude in recent years? Some have concluded from this observation that monetary aggregate (especially M1) targeting is a quite hopeless policy. ${ }^{22}$ Even recognizing the sizeable volatility in quarterly velocity growth, however, it is difficult to see how this is true. The results do suggest that policymakers will find it difficult to stabilize quarter-to-quarter fuctuations in

\footnotetext{
${ }^{20}$ There is no evidence that any of the other forecasting procedures can aid in improving upon the sample mean forecast. When the sample mean forecast error is regressed against the difference between forecasts, none of the coefficients on the difference are significantly different from zero. On the other hand, the sample mean forecast significantly reduced forecast errors associated with the other models for the four-quarter forecasts, indicating in this case that it is a stperior forecast procedure.

${ }^{21}$ Note also that large forecast errors in one direction, again, are offset by large forecast errors in the other, so the mean error for al models remains quite small. The mean forecast errors for the sample mean, triple exponential smoothing, Kalman filter and random walk forecasts are $0.21,0.41,0.90$ and 0.41 , respectively.

${ }^{22}$ For example, see Johm D. Paulus, vice president and economist, Goldman, Sachs \& Co., "Statement in Alternative Targets for Monetary Policy, Hearings before the Subcommittee on Domestic Monetary Policy of the Committee on Banking,
}

nominal spending. Such fine-tuning of the economy, however, has seldom, if ever, been the basis for recommending a monetary aggregate targeting procedure. Instead, monetary targeting procedures almost always have been advocated on the basis of achieving longterm economic goals.

While the sizeable volatility in quarterly velocity growth does imply a great deal of uncertainty about next quarter's GNP growth even if next quarter's money growth is known with certainty, it does not follow that it is particularly difficult to achieve longerterm GNP growth objectives. In fact, as a comparison of tables 1 and 2 indicates, the accuracy of velocity growth forecasts, in terms of root-mean-squared or mean absolute errors, improves as the length of time over which velocity growth is measured increases.

The ability to forecast velocity growth better over longer periods is related directly to the fact that quarterly velocity growth fuctuates randomly about a fixed value. Forecasting the individual fluctuations is impossible. Over time, however, these random fluctuations partially offset each other, which means that longer-term forecasting is possible, because forecasters can "hone in" on the fixed value. The longer the time horizon over which the forecasts are generated, the more accurate the forecast is likely to be. ${ }^{23}$

As an example of this phenomenon, let us put ourselves back in $1 / 1975$ and forecast nominal GNP growth from 1I/1975 through I/1983. In I/1975, we observed an average velocity growth of 2.79 percent from I/1959 to I/1975. Suppose we took this estimate of velocity growth as our forecast for quarterly velocity growth into the indefinite future, as the sample mean model suggests. Our forecast of velocity growth over the interval $1 / 1975-1 / 1983$ then would be 2.79 percent. Actually, velocity growth over this period was 2.48 percent. Our projection of velocity growth would have been in error by only 0.31 percentage points. Thus, our forecast of nominal spending growth would have been only 0.31 percentage points above what

Finance and Urban Affairs," U.S. House of Representatives 97 Cong. 2 Sess. (Government Printing Office, July 14, 1982), pp. $36-71$.

${ }^{23}$ This statement has a statistical foundation: suppose that quarterly velocity growth is independent and identically distributed $\mathrm{N} / \mu$, $\left.\sigma^{2}\right)$. Then, in this case average velocity growth over $N$ periods is distribated nomally with a mean $k$ and a variance $\sigma^{2} / N$. (See Gouri Bhattacharyya and Richard Johnson, Statistical Concepts and Methods (John Wiley \& Sons, 1977), esp. pp. 210-13.) The variance of the average declines as the number of periods in calculating the average increases. 
actually took place had we known the actual course of M1 growth.

The reader is reminded that this period - II/1975 to I/1983 - is one in which monetary aggregate targeting has been discredited because of: (1) supposed shifts in money demand and, most important, (2) financial innovations such as the introduction of ATS accounts, NOW accounts, money market mutual funds, allsavers certificates and money market deposit accounts, which supposedly altered the relationship of $\mathrm{M} 1$ to GNP. Yet, over this full period, a knowledge of average money growth plus a crude projection of velocity growth would have yielded a fairly accurate picture about the longer-term course of spending growth. ${ }^{24}$

\footnotetext{
The reader should not conclude from this analysis that the ecom nomic determinants of velocity growth are unimportant. These factors have been ignored here becatise they presumably would be difficult to forecast ex ante. For an analysis of these determinants, see Tatom, "Was the 1982 Velocity Dedine Unusual?" and Milton Friedman, "Why a Surge of Inflation Is Likely Next Year," Wall Street fournal, September 1, 1983.
}

\section{SUMMART AND CONOU USTONS}

This paper examined the predictability of velocity growth using several time series methods. The results are consistent with the notion that quarterly velocity growth fluctuates randomly about a fixed mean. The evidence suggests that forecasting next quarter's velocity growth using average velocity growth over some extended period of time is as effective as any other, more sophisticated, forecasting approaches. For onequarter forecasts analyzed here, this method performed as well as the more sophisticated techniques.

In addition, the accuracy of average velocity growth forecasts was found to improve with the time horizon over which the forecast is made. For example, forecasts of average velocity growth over four-quarter periods were significantly more accurate than those over one-quarter periods. This suggests that monetary policy is likely to be more successful in achieving longterm than short-term GNP growth objectives. Indeed, attempts to fine-tune conld well result in greater, rather than less, economic volatility. 